\title{
El Ente en Cayetano: Aproximación a su Significado E IMplicancias Metafísicas
}

\author{
Ceferino P. D. Muñoz
}

\begin{abstract}
RESUMEN: El siguiente trabajo pretende realizar un análisis en torno a la noción de ens en Cayetano. Sobre todo a partir de dos expresiones que introduce Tomás de Vio y que podrían tener asidero en la letra de Aristóteles; nos referimos a los términos esse essentiae y esse actualis existentiae. También nos detendremos en el origen doctrinal de dichas expresiones y en las consecuencias del uso de las mismas cuando Cayetano interpreta a Tomás de Aquino.
\end{abstract}

PALABRAS CLAVE: Ente. Cayetano. Aristóteles. Tomás de Aquino.

\section{Cayetano: entre Tomás y Aristóteles}

Cayetano no sólo fue un gran conocedor del Aquinate, sino también de Aristóteles, siendo incluso sus comentarios al Estagirita muy significativos, v.gr., Commentaria in Posteriora Analytica Aristotelis, Commentaria Super libros Aristotelis de Anima, Commentaria in Predicamenta Aristotelis, etc. En este sentido, hay autores para quienes en realidad el Cardenal habría recibido más influencias del pensamiento aristotélico que del tomista (e.g. GILSON, 1953 , p. 248) (e.g. GILSON, 1955, p. 136); incluso se ha sostenido que Aristóteles habría sido el gran obstáculo para una auténtica comprensión del pensamiento de Tomás de Aquino y que Cayetano habría sido el principal profeta del filósofo griego (e.g. PROUVOST, 1991, p. 188).

Habida cuenta de lo anterior, indagaremos la recepción del aristotelismo por parte de Cayetano, especialmente en lo que respecta a la concepción de ente y otras nociones derivadas que nuestro autor sostiene y despliega en sus escritos filosóficos. En concreto, analizaremos los términos esse essentiae y esse existentiae. Expresiones utilizadas por el Cardenal que, según algunas lecturas, podrían estar fuertemente vinculadas a la doctrina de Aristóteles. Dichas nociones tienen una notable relevancia, ya que son capitales al momento de

\footnotetext{
${ }^{1}$ CONICET - Facultad de Filosofía y Letras - UNCuyo (Mendoza). Email: ceferinomm@hotmail. com
} 
comprender la metafísica de Tomás de Vio y la repercusión que tuvo en sus diversos desarrollos especulativos, sobre todo a la hora de interpretar a Tomás de Aquino y su doctrina del actus essendi.

\section{El Lenguaje de ToMÁs de Vio SOBRe EL ENS}

En los textos de nuestro autor existen numerosas expresiones que merecen una atención particular al momento de entender su noción de ente. Desglosemos, pues, algunas de éstas para luego mostrar si existe o no algún tipo de interrelación entre ellas.

La primera de las nociones que trataremos es la de esse actualis existentiae. El Cardenal, al comentar el De ente et essentia, sostiene que ente (ens) es lo que tiene ser (habens esse) ${ }^{2}$; explica que el nombre ente se toma del ser mismo (ipsum esse) ${ }^{3}$ por el que la cosa es. Hasta aquí no parecería haber ningún tipo de incompatibilidad con la doctrina del Aquinate. Empero, poco después añade Cayetano que esse es "[...] aquello por lo que la cosa es o sea su existencia actual" 4 , igualando el ser a la existencia concreta. Este es uno de los puntos en donde el comentarista introduce una llamativa diferencia con el Aquinate en la noción esse.

De acuerdo a lo antedicho, Cayetano no concibe la noción de actus essendi tal como la entendió Tomás de Aquino ${ }^{5}$, porque aquél identifica

\footnotetext{
2 "Circa minorem primae rationis nota, quod ens, ut infra dicetur, significat id quod habet esse". CAYETANO, Tomás de Vio O. P. Commentaria in De ente et Essentia D. Thomae Aquinatis, Edición H. Laurent. Roma: Marietti, 1934, p. 80.
}

3 "Sed in Entis nomine duo aspici possunt, scilicet id a quo nomen Entis sumitur, scilicet ipsum esse, quo res est; et id ad quod nomen entis impositum est, scilicet id quod est". CAYETANO, Commentaria in De ente et essentiae, p. 87.

4 "In homine enim est considerare materiam in qua recipitur eius forma, et formam ipsam, quae est illius materiae actus, et essentiam humanam, quae nec est materia nec forma, et esse actualis existentiae, quo homo formaliter existit in rerum natura: unde fit, ut in istis substantiis duae compositiones pertinentes ad genus substantiae reperiantur”. CAYETANO, Commentaria in De ente et essentia, p.139.

${ }^{5}$ A fin de ver directamente la letra de Santo Tomás, se pueden consultar, entre otros, los siguientes textos tomasianos: In IV Metaph. II ("Esse enim rei quamvis sit aliud ab eius essentia, non tamen est intelligendum quod sit aliquod superadditum ad modum accidentis sed quasi constituitur per principia essentiae"), De Pot., VII, II ad 9 ("hoc quod dico esse est actualitas omnium actuum, et propter hoc est perfectio omnium perfectionum. Nec intelligendum est, quod ei quod dico esse aliquid addatur quod sit eo formalius, ipsum determinans, sicut actus potentiam: esse enim quod huiusmodi est, est aliud secundum essentiam ab eo cui additur determinandum. Nihil autem potest addi ad esse quod sit extraneum ab ipso, cum ab eo nihil sit extraneum nisi non ens, quod non potest esse nec forma nec materia. Unde non sic determinatur esse per aliud sicut potentia per actum, sed magis sicut actus per 
el esse o actus essendi con la existencia actual o esse actualis existentiae, considerándolo como una realidad distinta de la esencia real de la criatura ${ }^{6}$. Por tanto, para nuestro autor el ente sería un compuesto de dos cosas distintas: la esencia y el esse ${ }^{7}$. Entonces, Cayetano no sólo cosifica el esse, sino que sostiene que éste sería la última actualidad que un ente obtiene como resultado de ser producido por una causa eficiente. Sin embargo, nada más alejado de la letras de Santo Tomás, para quien el esse no es una cosa sino un acto por el que cada sustancia es un ser. Explica Tomás de Vio:

[...] siendo el ser la actualidad última de una cosa, y por ser lo último en generación lo primero en intención, ser se hallará en el género de sustancia como principio formal último de la sustancia misma; porque, precisamente, algo se coloca en el género de sustancia porque es capaz de ser sustancial $[\ldots]^{8}$.

Es decir, al afirmar lo anterior, Cayetano estaría restringiendo el esse a la categoría en la cual está el esse; así el ser se reduciría a la sustancia. Sin dudas esta puede ser una posición filosóficamente sostenible, pero ciertamente no es la del Aquinate, por ello escribe Gilson (1955, p. 119): “[...] según Santo Tomás, el ipsum esse de la sustancia no es reductible a la sustancia, éste es el acto que hace de la sustancia un ente. Como todo habens esse, la sustancia es el receptor de esto que hace de ella un ente".

Estas desviaciones ya fueron notadas - antes que por los estudiosos contemporáneos- por otro gran comentador del Aquinate, Domingo Bańez. A este autor le llama poderosamente la atención la insistencia de Cayetano

potentiam"); De Pot., V, IV ad 3 (“esse substantiae est enim actus essentiae... non est pars essentiae..."). Para precisar más esta noción, pueden confrontarse otros muchos textos de Santo Tomás: II, 54, 3; De subst. separ., 8; De spir. creat., a. I c, etc. También se puede consultar el completo estudio de Cornelio Fabro (1969, p. 110-113). Allí se citan muchos más textos de Santo Tomás referidos al esse.

6 "Quoad secundum, opinio S. Thomae ab eo posita in II contra Gentiles, cap. LII, est quod in omni creatura quidditas et eius esse actualis existentiae distinguuntur realiter". CAYETANO, Commentaria in De ente et essentia, p. 143.

7 "S. Thomas autem ex fundamentis in dubitatione praecedenti positis opinatur intelligentias et quamlibet creaturam esse compositas ex actu et potentia, sicut ex duabus rebus distinctis realiter, esse scilicet et essentia". CAYETANO, Commentaria in De ente et essentia, p. 161.

8 "Ad hoc dicitur quod cum esse sit ultima actualitas rei et ultimum in generatione sit primum in intentione, esse erit in genere substantiae ut principium formale ultimatum ipsius substantiae; per hoc enim res reponitur in genere substantiae, quia est capax esse substantialis, etenim differentiae in omnibus generibus, ut infra declarabitur, sumuntur ab ordinc ad ipsum esse”. CAYETANO, Commentaria in De ente et essentia, p. 159. 
en identificar el acto de ser tomista con el ser real que el sujeto adquiere al término de la generación. Para Bañez, el esse tomista no es el actus ultimus en el sentido de la actualidad obtenida finalmente por el sujeto en su devenir, sino, más bien, su actus primus, aquel sin el cual el sujeto del devenir no sería el mismo ser y sin el cual ni siquiera habría devenir. García Cuadrado ejemplifica la crítica bańeciana diciendo que el acto de ser de Santo Tomás no es el que hace que el embrión llegue al término de su evolución biológica, sino que es el acto que hace que el mismo embrión exista (GARCÍA CUADRADO, 1998, p. 65-66). Por tanto, cuando el Angélico sostiene que el esse es el acto primero y último, no se refiere a que sea último en el tiempo, sino que es último porque es acto supremo, allende el cual no existe otro'. Por el contrario, de acuerdo con los textos antes citados, Cayetano no lo entendió de ese modo.

Además de la expresión esse actualis existentiae, que recién se explicó, Cayetano incorpora otra: esse essentiae (ser de la esencia) o su equivalente esse quiditativum (ser quiditativo). Y estrechamente relacionado con estas dos nociones se ubica la división de Cayetano entre ens nominaliter y ens participialiter o verbaliter, o el ente como acto signado y como acto ejercido ${ }^{10}$. Así el esse essentiae sería el ens nominaliter mientras que el esse existentiae sería el ens participialiter o ens verbaliter.

Sabemos que el término ens (ente) puede entenderse como nombre o como verbo. Como nombre o sustantivo significa un ente, lo que es, cualquiera de las cosas que son, lo que tiene ser. Como verbo o participio significa el hecho mismo que una cosa sea, lo que efectivamente ejerce el acto de ser, lo que está siendo. Así como la palabra estudiante, si se toma como nombre se aplica a aquella persona cuyo acto propio es el estudiar, aunque de hecho no lo esté haciendo. En cambio tomada como participio se refiere sólo al que de hecho está estudiando; al igual que por viviente puede entenderse tanto aquello cuyo acto propio es vivir como aquello que vive en acto. A partir

9 BANEEZ, D. Scholastica commentaria in Primam Partem Summae Theologicae D. Thomae Aquinatis, Madrid-Valencia: Luis Urbano, t. I, 1934, ad 1, 3, 4; p. 142: "Cajetanum etiam De ente et essentia, c. 5, q. 11, ad 8 argumentum ait, existentiam substantiae esse substantiam [...]” etc. — p. 145: "Et idcirco non placet mihi explicatio Caietani ubi supra, videlicet, quod proptera dicatur existentia ultima actualitas rei quia est ultimum in generatione. Certe hic modus loquendi quod ipsum esse sit ultima actualitas rei, raro invenitur apud Divum Thomam. Inventes in quaestione unies De anima, art. 6 , ad $2 \mathrm{~m}$, ubi inquit, quod ipsum esse est actus ultimus, qui partieipabilis est ab omnibus. In quo loco, si sequentia legeris, intelliges quomodo ipsum esse sit actus ultimus, nimirum supremus excellentissimus, qui omnes etiam alios actus perficit".

${ }^{10}$ Cfr. CAYETANO, Commentaria in De ente et essentia, p. 117-118. 
de estas distinciones, Cayetano le da ciertas características específicas al ente, según se lo tome como nombre o como participio.

El ens nominaliter es llamado lo que es o puede ser, pero no se quiere expresar con ello la existencia de hecho, por ello se habla de connotación del esse in actu signato (el ser en acto expresado). Este es el esse essentiae o esse quiditativum, el cual ya tiene una cierta realidad: es la esencia o naturaleza universal, por ejemplo: hombre.

Por el contrario, el ens participialiter, dice lo que de hecho es, o connota el esse in actu exercito (el ser en acto ejercido) lo que sólo puede ser afirmado hablando de la experiencia, dado que el hecho es únicamente objeto de experiencia, a saber, el hombre concreto. Dice Cayetano al glosar la Suma de Teología:

[...] en efecto, es manifiesto que el ser puede tomarse de dos maneras, a saber, como acto ejercido de la misma existencia y [como acto signado] por modo de la quididad. Y lo que como ejerce la existencia, agrega sobre si misma como lo que es. Y por consecuencia, como objeto del intelecto, es abstracto $[\ldots]^{11}$.

\section{EsenCia y existencia en Aristóteles y en Cayetano}

Tal vez uno de los motivos por los que se ha sostenido que Cayetano sigue más al Estagirita que al Aquinate en lo referente a la metafísica es que se ha intentado asimilar algunas nociones del mismo Aristóteles con otras usadas por el propio comentador de Gaeta.

En el Libro II Capítulo VII de los Segundos Analíticos, el filósofo griego expone las diferencias entre la definición y la demostración:

Pues la definición lo es del qué es y de la sustancia; las demostraciones, en cambio, parecen presuponer y dar por sentado todas el qué es, v.g.: las matemáticas [presuponen] qué es la sustancia y qué es lo impar, y

\footnotetext{
11 "[...] iam enim patet quod esse dupliciter sumi potest: scilicet in actu exercito ipsius existentiae; et per modum quidditatis. Et quod ut exercet existentiam, addit supra seipsum ut quod quid est. Et consecuenter ut obiectum intellectus, est abstractius [...]" CAYETANO, Tomás de Vio O. P. (en Sancti Thomae Aquinatis, Summa Theologica cum comentario Cardenali Caietani, de la Opera Omnia. Romae: Leonina, 1883. I, q. 82, a. 3; XV, p. 301. La distinción entre acto signado y acto ejercido también puede ser consultada, hasta lo que sabemos, en otras dos obras del mismo autor: Commentaria in De ente et essentia, p. 87 y De nominum analogia. Texto latino según edición Zammit O. P. (con notas del P. Zammit), trad. y notas de Guido Soaje Ramos. Mendoza: Universidad Nacional de Cuyo, Instituto de Filosofía, 1949, p. 118.
} 
las demás [ciencias], de manera semejante. Además, toda demostración demuestra algo acerca de algo, v.g.: que es o que no es, en cambio en la definición no se predica nada de otra cosa distinta, v.g.: ni animal acerca de bipedo ni esto acerca de animal, tampoco figura acerca de superficie: pues la superficie no es una figura, ni la figura una superficie. Además, una cosa es demostrar el qué es y otra [el hecho de] que es. Así pues, la definición indica qué es [tal cosa], la demostración, en cambio, indica que tal cosa es o no es con relación a tal otra ${ }^{12}$.

Lo que quiere decir Aristóteles, entonces, es que la esencia será objeto de definición, sea de un ente físico como el hombre o de uno matemático como el triángulo; mientras que la existencia será objeto de demostración, i.e, de que algo es o que no es. En este sentido, la definición muestra qué es una cosa, pero no que esta cosa exista o no. Y unas líneas más adelante sostiene el Estagirita: “[...] tampoco [se da] el qué es sin el hecho de que sea: pues es imposible saber qué es [una cosa] ignorando si es"13. En otras palabras, no hay esencia sin existencia o la definición de una cosa real supone la existencia de lo definido.

Por ello Aristóteles afirmará que si bien la definición indica una cosa única, "[...] qué es el hombre y [el hecho] que el hombre sea son cosas distintas" ${ }^{14}$. Por lo general se entiende que el Filósofo acá se está refiriendo a la conocida distinción entre esencia y existencia, es decir, al contenido inteligible de un ente y a la realidad fáctica de ese mismo ente. (e.g. ECHAURI, 1975, p. 120).

Ahora bien, ¿tales distinciones podrían aplicarse a las usadas por Cayetano? ¿Podría decirse que la esencia y la existencia aristotélica se equiparan con el esse essentiae y el esse actualis existentiae que postula el Cardenal? Por nuestra parte, creemos que no hay una correspondencia total, puesto que entre el binomio de conceptos mencionados existen importantes diferencias.

Por un lado, la noción esse essentiae indica algo que puede llegar a ser o una realidad bajo un aspecto estático, y el esse actualis existentiae refiere a

\footnotetext{
${ }^{12}$ ARISTÓTELES, Analíticos Posteriores, II, 90b 30-91a 1. Trad. Miguel Candel Sanmartin. Madrid: Gredos, 2007. Hemos preferido el uso del término sustancia en lugar de entidad; éste último es el que utiliza el traductor para ousía. Las cursivas y las reposiciones son del texto original, lo mismo en el resto de las citas.

${ }^{13}$ ARISTÓTELES, Analíticos Posteriores, II, 93a 19-22.

${ }^{14}$ ARISTÓTELES, Analíticos Posteriores, II, 92b 8-10.
} 
la existencia actual o a una realidad dinámica. Sin embargo, la esencia y la existencia aristotélica no indican un ente posible por un lado y otro actual por el otro, sino la esencia real de una cosa y la existencia efectiva de la misma cosa, pero en el mismo ente. Para el Estagirita la esencia es lo que la cosa actual es, mientras que para el comentador de Gaeta será la pura posibilidad de un ente que aún no tiene existencia actual. Empero, podría decirse que se da una coincidencia entre la existencia de Aristóteles y el esse actualis existentiae de Cayetano, en cuanto ambos refieren al objeto propio de la experiencia.

Según lo anterior, creemos que la terminología que usa Cayetano - esse essentiae y esse actualis existentiae - no son fruto de la lectura directa del maestro del Liceo o no se deducen inmediatamente de sus escritos.

\section{EL ORIGEN DE LAS EXPRESIONES ESSE ESSENTIAE Y ESSE ACTUALIS EXISTENTIAE}

Según la autorizada opinión de algunos estudiosos contemporáneos, el binomio esse essentiae y esse actualis existentiae se remontaría antes bien a Avicena. Al respecto dice Fabro (1957, p. 419):

La terminología de esse essentiae y esse existentiae, recordada por Heidegger, no es de Santo Tomás, sino de su adversario y de la fuente de Scoto que es Enrique de Gante: en la concepción escotista, y en general en el extrinsecismo aviceniano asumido por la mayor parte de la Escolástica, el momento decisivo de la realidad de lo real es el pasaje de la posibilidad a la realidad y esto se resuelve en el pasaje de la esencia posible (esse essentiae) a la esencia realizada (esse existentiae).

Asimismo, Gilson, en consonancia con Fabro, cree que la expresión esse essentiae es deudora de la distinción aviceniana del triple estado de la esencia, a saber, en la mente, en las cosas y considerada en sí misma. De este último modo es como la esencia se daría si no hubiera ni mentes ni cosas. En tal sentido, el medievalista francés estima que la esencia en este tercer estado se correspondería con las ideas platónicas (e.g. GILSON, 2005, p. 109). Explica Gilson (2005, p. 110):

Lo que ahora estamos presenciando, en la filosofía de Avicena, es la aparición de un curioso tipo de ser, el esse essentiae de Enrique de Gante y de tantos otros filósofos escolásticos. No es un ser de existencia (esse existentiae), aunque es un cierto tipo de ser, a saber: aquel que pertenece 
a la esencia como tal, independientemente del hecho de que esté o no esté actualizado en algún sujeto cognoscente o en alguna cosa individualmente existente.

Para Enrique de Gante, la raíz última de las cosas creadas es su esencia, la cual se identifica con una idea divina que tiene un ser propio, y a este ser propio se lo denomina esse essentiae (e.g. PROUVOST, 1996, p. 95). Al parecer, lo que hizo Enrique de Gante fue reforzar la enseńanza de Egidio Romano, para el cual la esencia es una realidad eterna que no puede ser creada. Dios sería la causa eficiente de la cosa, pero sólo de su existencia, mientras que de la esencia sería su causa ejemplar (e.g. GARCÍA CUADRADO, 1998, p. 57).

Entonces, Cayetano al asumir el léxico esse essentiae, casi indefectiblemente estaría asumiendo los planteos y problemas que este léxico suscita: en este caso, que el ser sería una nota o accidente de la esencia, y que ésta tendría un cierto tipo de ser antes de pasar a la existencia concreta. Lo sorprendente es que el comentador de Gaeta no toma este vocabulario para criticarlo sino que lo incorpora como propio, y lo que es más audaz aún, se lo atribuye al mismo Santo Tomás .

Por otro lado, Ralph McInerny en uno de sus últimos libros Praeambula Fidei: Thomism and the God of the Philosophers, renueva la discusion en torno a las nociones usadas por Cayetano y emprende un embate contra la postura gilsoniana. El filósofo norteamericano explica que el Cardenal sólo usa una vez la frase esse actualis existentiae, y por esta única mención Gilson lo ha acusado de perder de vista lo que el Aquinate quería decir (e.g. MCINERNY, 2006, p. 62-63).

Es verdad que al comentar el De ente et essentia, el Cardenal utiliza en pocas ocasiones la expresión mencionada -aunque no una, como sostiene McInerny-, sin embargo dicha expresión se corresponde con otra ya explicada y también mencionada por Cayetano en la misma obra, a saber, ens participialiter. Además, v.gr. en sus Comentarios a los Analiticos posteriores de Aristóteles ${ }^{15}$ y a la Suma de Teología, el Cardenal también usa la expresión esse actualis existentiae ${ }^{16}$.

${ }^{15}$ CAYETANO, Tomás de Vio, O. P., Commentaria in Posteriora Analytica Aristotelis. Textus ex editione Lugdunensi, 1579, exerptus et a E. Babin et W. Baumgaertner. Exaratus et emendatus. Liber I, 1950. Québec: L’Univertité Laval. Faculté de Philosophie. p. 11 y 17 y Liber II (1951), p. 71.

${ }^{16}$ CAYETANO, Tomás de Vio O. P. (en Sancti Thomae Aquinatis, Summa Theologica cum comentario Cardenali Cayetani, de la Opera Omnia. Romae: Leonina, 1883. I, q.3. a.5., p. 44; q.28. a.2. p. 322; 
Leo Elder es otro importante tomista actual que cree que la distinción cayetana se aparta de la doctrina tomasiana. Este autor en una reciente publicación sostiene que los términos esse essentiae y esse actualis existentiae no son para nada convenientes al lenguaje tomasiano y remoza la tesis gilsoniana de que tal vocabulario tendría sus raíces en la influencia escotista y antes aún en Avicena (ELDERS, 2011, p. 2).

\section{A MODO DE CONCLUSIÓN}

La metafísica de Aristóteles no parece haber buscado un principio que explicara la totalidad de lo real, esto es, no parece haber indagado sobre un principio que trascendiera el mero hecho de la misma existencia de las cosas reales, lo que, por otra parte, es lógico dado que para él el cosmos era inengendrado. El Estagirita centra su investigación metafísica en la sustancia, y la sustancia por antonomasia o en sí es la forma ${ }^{17}$. Allí radica para el Filósofo el último fundamento o causa de lo real (REALE, 2003, p. 168).

Por otro lado, para los teólogos y filósofos de la época de Cayetano si algún concepto no se encontraba en Aristóteles entonces no pertenecía a la filosofía (e.g. GILSON, 1961, p. 173). Y es sabido que la noción de un actus essendi dado y sostenido por Dios en las criaturas no se hallaba en el maestro del Liceo. Así, por tanto, para el Cardenal, no se trataría de una noción filosófica per se loquendo.

En este contexto pueden entenderse las fuertes aseveraciones de Gilson (PROUVOST, 1991, p. 188): “[...] una cosa está clara al menos en mi cabeza: el peor enemigo de Santo Tomás, incluso en la orden dominica, ha sido Aristóteles, cuyo profeta es Cayetano". Estas palabras no deben prestarse a malentendidos. No es que el medievalista francés culpe al pensador griego de las falencias interpretativas de Cayetano, sino que en todo caso el responsable de no haber ido más allá de Aristóteles es el mismo Cardenal. Como lo explica el profesor Saranyana (2011, p. 429):

[...] recuérdese que lo propio del tomismo es completar la posición aristotélica con el descubrimiento de la trascendentalidad del esse. Así pues, Cayetano sería, pura y llanamente, un aristotélico convencido, como

II, q.27 a.2., p. 223, 224, 225, 226, 227).

${ }^{17} \mathrm{Si}$ bien per se la sustancia por excelencia es la forma, quad nos es el compuesto. Para ver esta afirmación en detalle, cf. ARISTÓTELES, Metafisica, VII, cap. 4-6 y 10-12. 
le correspondía por haberse formado en Padua, aunque camuflado bajo ropaje tomista $[\ldots]$.

Como bien dijimos al principio de este trabajo, el comentador italiano fue un gran conocedor del pensamiento del Estagirita, y sin lugar a dudas hubo una fuerte influencia de Aristóteles en él. Pero creemos que fue mayormente un tipo de aristotelismo - de los tantos que se suscitaron en torno al Estagirita - el que incidió en el Cardenal. Nos referimos concretamente al aristotelismo paduano $^{18}$. Recordemos que Cayetano estudió y enseñó en Padua, uno de los focos del averroísmo latino ${ }^{19}$ por esa época. Este tipo de aristotelismo pretendió hacer una lectura de Aristóteles lo más pura posible, sin contaminación alguna de la teología cristiana. Por ello el Aristóteles averroísta llevaba a sostener tesis contrarias a la fe, conduciendo finalmente a un filosofismo escindido de la teología (e.g. FILIPPI, 2010, p. 29-46), o a un ejercicio de la razón filosófica separado del intellectus fidei. En este contexto, no es de extrañar, además, que Cayetano haya llegado a algunas conclusiones tan distantes del Aquinate, como la que sostenía que no es posible demostrar por la razón la inmortalidad del alma (MANZANEDO, 1999, p. 309-340) o aquella que afirmaba que las cinco vías tomasianas concluyen en la existencia de un ser superior pero al que se resistía a llamarle Dios (e.g. GELONCH; MUÑOZ, 2012, p. 330-333).

MUÑOZ, Ceferino P. D. Ente in Cajetan: understanding its meaning and metaphysical implications. Trans/Form/Ação, Marília, v. 36, n. 3, p. 23-34, Set./Dez., 2013.

\begin{abstract}
The following work pretends to analyze the notion of ens in the work of Cardinal Cajetan (Thomas de Vio). In particular, we discuss two expressions which Cajetan introduced and could have a grip on the letter of Aristotle: esse essentiae and esse actualis existentiae. We also discuss the doctrinal origin of these expressions and the consequences of Cajetan's use of them in interpreting Thomas Aquinas.
\end{abstract}

KEYWORDS: Being. Cajetan. Aristotle. Thomas Aquinas.

\footnotetext{
${ }^{18}$ Autores como Kristeller prefieren hablar de aristotelismo secular italiano en lugar de aristotelismo paduano. Cfr. KRISTELLER, 1986, p. 135.

${ }^{19}$ Sabemos de lo problemático que resulta el término averroísmo latino. Para profundizar en esta cuestión, remitimos al completo estudio de MINECAN, 2010, p. 63-85.
} 


\section{REFERENCIAS}

\section{FUENTES}

ARISTÓTELES. Metafisica. Traducción Tomás Calvo Martínez. Madrid: Gredos, 2007. . Analiticos Posteriores. Traducción Miguel Candel Sanmartín. Madrid: Gredos, 2007.

BAÑEZ D. Scholastica commentaria in Primam Partem Summae Theologicae D. Thomae Aquinatis, t. I. Madrid-Valencia: Luis Urbano, 1934.

BUSA SJ, R. (auctore). Thomae Aquinatis Opera Omnia: cum hypertextibus in CD-ROM. Milano: Editoria Elettronica Editel, 1992.

CAYETANO, Tomás de Vio O.P. Commentaria in De ente et Essentia D. Thomae Aquinatis, Edición H. Laurent. Roma: Marietti, 1934.

. en Sancti Thomae Aquinatis, Summa Theologica cum comentario Cardenali Caietani, de la Opera Omnia, t. IV y V. Romae: Leonina, 1883.

. Commentaria in Posteriora Analytica Aristotelis. Textus ex editione Lugdunensi (1579) exerptus et a E. Babin et W. Baumgaertner. Exaratus et emendatus. Liber I (1950) y Liber II (1951). Québec : L’Université Laval. Faculté de Philosophie.

. Sobre la Analogía de los Términos. Acerca del Concepto de Ente. Texto latino según ed. Zammit O.P. (con notas de Zammit). Traducción y notas de Guido Soaje Ramos. Mendoza: U.N.Cuyo. Instituto de Filosofía, 1949.

\section{LIBROS Y ARTÍCULOS}

ELDERS, L. Cayetano, comentador de la Suma de teología de Santo Tomás. In: http:// bibliotecadigital.uca.edu.ar/repositorio/ponencias/cayetano-comentador-suma-teologiatomas.pdf. Consultado el 27 nov. 2012.

FABRO, C. Tomismo e Pensiero Moderno. Roma: Pontificia Università Lateranense, 1969. . Dall'essere all'esistente. Brescia: Morcelliana, 1957.

FILIPPI, S. La restitución de valor inteligible al conocimiento sensible en el realismo medieval. Scripta Mediaevalia, v. 3, p. 29-46, 2010.

GARCÍA CUADRADO, J. Á. La luz del intelecto agente. Estudio desde la metafísica de Bañez. Pamplona: EUNSA, 1998.

GELONCH, S.;MUÑOZ, C. Algunas inflexiones en la cuestión Si Dios es: santo Tomás, Cayetano y Platón. In: HERRERA, J. J. (Ed.). Fuentes del Pensamiento Medieval. San Miguel de Tucumán: UNSTA, 2012, p. 327-339. 
MUÑOZ, C. P. D.

GILSON, E. El ser y los filósofos. Trad. Santiago Fernández Burillo. Pamplona: EUNSA, 2005.

. Autour de Pomponazzi. Archives d'histoire doctrinale et littéraire du Moyen Age, 28, p. 163-279, 1961.

. Cajétan et l'humanisme théologique. Archives d'histoire doctrinale et littéraire du Moyen Age 30, p. 113-136, 1955.

. Cajétan et l'existence. Tijdschrift voor Philosophie, v. 15, p. 267-286, 1953.

KRISTELLER P.O. El Pensamiento Renacentista y Las Artes. Traducción Bernardo Moreno Carrillo. Madrid: Taurus, Ensayistas Series, v. 26, 1986.

MANZANEDO, M. La inmortalidad del alma humana según Cayetano. Angelicum v. 76, p. 309-340, 1999.

MCINERNY, R. Praeambula Fidei: Thomism and the God of the Philosophers, Washington: The Catholic University of America Press, 2006.

MINECAN, A, M. Introducción al debate historiográfico en torno a la noción de “averroísmo latino”. In: SEMINARIO DE HISTORIA DE LA FILOSOFÍA. Anales... V. 27, p. 63-85, 2010.

PROUVOST, G. Thomas d'Aquin et le thomistes. París: Les Éditions du Cerf, 1996.

(Ed.). Étienne Gilson et Jacques Maritain. Deux approaches de l'etre. Correspondance 1923-1971. Paris: Vrin, 1991.

REALE, G., Guía de lectura de la metafísica de Aristóteles. Trad. J. M López de Castro. Barcelona: Herder, 2003.

SARANYANA, J. I. Historia de la Filosofía Medieval. Pamplona: EUNSA, 2011.

Recebido em: 28.11.2012

Aceito em: 18.04.2013 